\title{
Scientific Evidence for the Addictiveness of Tobacco and Smoking Cessation in Tobacco Litigation
}

\section{Sungwon Roh}

Department of Psychiatry, Hanyang University College of Medicine, Seoul, Korea

Smokers keep smoking despite knowing that tobacco claims many lives, including their own and others'. What makes it hard for them to quit smoking nonetheless? Tobacco companies insist that smokers choose to smoke, according to their right to self-determination. Moreover, they insist that with motivation and willpower to quit smoking, smokers can easily stop smoking. Against this backdrop, this paper aims to discuss the addictive disease called tobacco use disorder, with an assessment of the addictiveness of tobacco and the reasons why smoking cessation is challenging, based on neuroscientific research. Nicotine that enters the body via smoking is rapidly transmitted to the central nervous system and causes various effects, including an arousal response. The changes in the nicotine receptors in the brain due to continuous smoking lead to addiction symptoms such as tolerance, craving, and withdrawal. Compared with other addictive substances, including alcohol and opioids, tobacco is more likely to cause dependence in smokers, and smokers are less likely to recover from their dependence. Moreover, the thinning of the cerebral cortex and the decrease in cognitive functions that occur with aging accelerate with smoking. Such changes occur in the structure and functions of the brain in proportion to the amount and period of smoking. In particular, abnormalities in the neural circuits that control cognition and decision-making cause loss of the ability to exert self-control and autonomy. This initiates nicotine dependence and the continuation of addictive behaviors. Therefore, smoking is considered to be a behavior that is repeated due to dependence on an addictive substance, nicotine, instead of one's choice by free will.

Key words: Tobacco, Nicotine, Addiction, Smoking cessation

\section{INTRODUCTION}

Smoking is known as one of the top 3 disease-causing factors worldwide, along with hypertension and air pollution [1]. The World Health Organization reported that tobacco claims

Received: September 20, 2016 Accepted: November 29, 2017

Corresponding author: Sungwon Roh, MD, PhD

Department of Psychiatry, Hanyang University College of Medicine,

222 Wangsimni-ro, Seongdong-gu, Seoul 04763, Korea

E-mail: swroh@hanyang.ac.kr

This is an Open Access article distributed under the terms of the Creative Commons Attribution Non-Commercial License (http://creativecommons.org/licenses/bync/4.0/) which permits unrestricted non-commercial use, distribution, and reproduction in any medium, provided the original work is properly cited. half of smokers' lives and that smoking causes about six million deaths every year [2]. Among these deaths, over 600000 occur in non-smokers exposed to secondhand smoke.

Because of all the harms that smoking causes to smokers' own health as well as to others, many smokers attempt to stop smoking. However, the quit rates are low. Likewise, it is not easy to stop smoking based on willpower alone. For instance, smokers with lung cancer or cardiovascular diseases (for which tobacco is a critical risk factor) commonly keep smoking, failing to quit either before or after surgery for cancer or their heart condition. This suggests that smoking and smoking cessation cannot be considered to be controlled by smokers' reasonable decisions and free will alone. 
A litigation claim for damages by smoking brought by the Korea National Health Insurance Service against 3 tobacco companies, including KT\&G, British American Tobacco Korea, and Philip Morris Korea (Seoul Central District Court 2014 Ga Hap 525054 case) in April 2014 is ongoing. There have been arguments regarding various issues, and the focus of the eighth argument was the addictiveness of tobacco.

The statement "Addictiveness of tobacco and smokers' ability to quit smoking," submitted by the defense counsel of the tobacco companies [3], contains content that contradicts the scientific evidence in many ways. In this paper, the author intends to discuss the scientific evidence of the addictiveness of tobacco as a counterargument against that statement, based on the state of the art of medical research on subjects including smoking, tobacco, nicotine, and smoking cessation.

\section{ADDICTIVENESS OF TOBACCO}

According to the statement of the tobacco companies, nicotine is distinct from other addictive substances since it does not cause abuse or intoxication [3]. Regarding abuse, in the Diagnostic and Statistical Manual of Mental Disorders, fifth edition (DSM-5) (the latest version published by the American Psychiatric Association in 2013), the distinction between abuse and dependence that had been used for substance use disorders in the prior version no longer exists [4]. Instead, the concepts of abuse and dependence are merged into a single type of disease, called "substance use disorders."

In case of tobacco, the corresponding disease is known as "tobacco use disorder." Intoxication is a negative behavioral or psychological change that occurs in the central nervous system due to physiological influences during or immediately after consuming a substance. For alcohol, the symptoms of intoxication include unpleasant responses, such as slurred speech, unstable gait, nystagmus, impaired attention and/or memory, stupor, and coma. However, the 11 criteria for diagnosing tobacco use disorder in the DSM-5 do not include symptoms related to intoxication [4]. In other words, the presence of intoxication does not affect the diagnosis of a substance use disorder; it is merely a manifestation of the immediate effects of a given substance.

The logic that nicotine is not an addictive substance because it does not cause intoxication leads to the unreasonable conclusion that caffeine, which can cause intoxication, is a more serious addictive substance than nicotine. Thus, the con- cepts of intoxication and addiction should not be confused even though both terms are translated into the same word in Korean language. The meaning of the former is as presented above. Addiction is commonly used to refer to obsessive and habitual substance use. However, as the word carries negative and extreme connotations, a more neutral term, "substance use disorder," is preferred, which involves a broader range of mild to severe symptoms. The absence of intoxication does not mean that a given substance is not addictive.

According to the statement of the tobacco companies [3], tobacco withdrawal symptoms are subjective and non-specific. Moreover, the reasons why smokers resume smoking after cessation are related to situational cognition and social values, rather than physical responses due to the nicotine withdrawal. Furthermore, they argue that no correlation exists between the seriousness of withdrawal symptoms and the success of cessation.

Nonetheless, tobacco withdrawal symptoms, including irritability, anxiety, impaired attention, increased appetite, restlessness, depression, and insomnia, are common: nearly $50 \%$ of smokers who quit smoking for 2 or more days experience 4 or more of the above 7 symptoms [4].

Smoking cessation leads to clinically severe suffering, to the point of agony. Nicotine withdrawal symptoms affect one's ability to continue smoking cessation, which may result in failure in smoking cessation and reuse of tobacco [4]. According to the Fagerström Test for Nicotine Dependence (FTND), which evaluates individuals' dependence on nicotine, the more severe withdrawal symptoms are, the stronger the nicotine dependence [5]. Moreover, the more severe one's nicotine dependence is, the more likely the person is to resume smoking [6].

The argument of the tobacco companies that the changes in the brain caused by smoking are easily reversible, as the brain recovers to its previous state in 12 weeks from the time of smoking cessation, is cited based on findings regarding changes in the availability of the nicotinic acetylcholine receptor after smoking cessation [7]. The nicotinic receptor increases by 3 to 4 times in the cerebral cortex due to smoking, and that level does not change until a month after smoking cessation. The level reverts to normal only when cessation lasts for 6 to 12 weeks $[7,8]$.

The paper concludes that the maintenance of the change in the availability of the nicotinic receptor due to smoking at significant levels for a long period of time is what makes smoking cessation challenging. According to recent studies, with in- 
creased pack-years, the cerebral cortex thins more, which is linked with a decrease in cognitive functions $[9,10]$. Moreover, a maximum of 25 years of smoking cessation was found to be necessary for these changes in the cortex to recover [9].

Smokers' brains undergo structural changes in comparison to the brains of non-smokers, proportionally to the amount of smoking. The thinning of smokers' cerebral cortex in the frontal lobe suggests functional impairment in the circuitry of the brain that regulates rewards, impulse control, and decisionmaking [10]. Another study reported that a longer smoking history was associated with lower performance in cognitive functions, including intelligence in general, visuospatial learning ability, memory, and fine coordination [11].

Some studies have compared the addictiveness of tobacco and other addictive substances. One of the most well-known studies, by Nutt et al. [12] in the UK, ranked tobacco third in dependence, following heroin and cocaine. Tobacco dependence was more highly rated than that of other substances, including alcohol, benzodiazepines, methamphetamine, and cannabis [12]. High dependence can be understood as the cumulative rate of users who try a substance out of curiosity and wind up being dependent on it: nicotine showed the highest rate $(67.5 \%)$, followed by alcohol $(22.7 \%)$, cocaine (20.9\%), and cannabis (8.9\%) [13].

Another study conducted by the same research team examined the rates of remission from life-time substance dependence among patients with substance dependence. Nicotine showed the lowest rate, followed by alcohol, cannabis, and cocaine, in order [14]. Likewise, tobacco causes stronger dependence than other addictive substances. Treating tobacco use disorder is therefore very challenging.

\section{SMOKERS' ABILITY TO QUIT SMOKING}

According to a 2016 report on social survey by Statistics Korea [15], approximately $50.4 \%$ of smokers had attempted to quit smoking during the last year. In contrast, despite the variability across treatment modalities, the general quit rates remain between a mere 5 and 30\% [16]. According to the statement of the tobacco companies, anyone can quit smoking, as $96 \%$ of those who succeeded in quitting in Korea did so through their own willpower. As smoking is a voluntary act, they argue, we can start, continue, or quit smoking by our own free will [3].

Their statement continues to state that when smokers re- sume smoking after quitting, that should be understood as a choice of what they had previously enjoyed. Quitting smoking is possible. However, tobacco is an addictive substance. As mentioned earlier, although remission from life-time substance dependence rates vary by substance, that of tobacco was lower than the corresponding rates for alcohol or other substances [14]. Furthermore, the possibility of recovering from addiction does not mean that the substance that caused the addiction is not addictive.

In other words, although there are cases of people who succeed in abstaining from other substances, such as alcohol and opioids, as is the case for smoking cessation, this does not change the fact that those substances are addictive. The observation that those who used to be smokers, or $96 \%$ of quitters, were successful in smoking cessation by their willpower does not mean that $96 \%$ of smokers quit smoking through their willpower alone.

Extensive research has documented that quit rates vary by therapy method: self-quit has a quit rate, $5 \%$; self-help books or physician advice, 10\%; nicotine patch or gum, 15\%; medication plus advice or behavioral therapy alone, $20 \%$; and medication plus group therapy, 30\% [16-18]. Even with such diverse therapies, quit rates do not exceed $50 \%$.

As such a large portion of smokers have attempted to quit smoking through their own willpower, a high percentage of quitters did so through their own willpower; nonetheless, quitting through one's own willpower does not lead to high quit rates. In short, approximately 20 times as many smokers as succeed in quitting through willpower are estimated to fail and resume smoking.

It has been reported that heavier smokers are more strongly dependent on nicotine and have more severe withdrawal symptoms when quitting. They are also more likely to fail to quit [19]. In contrast, a shorter duration of smoking [20] and lower smoking amounts [21] lead to higher quit rates. This can be documented through FTND, which evaluates one's severity of nicotine dependence [5], and the Heaviness of Smoking Index [22]. Both instruments include a question about cigarettes per day. Thus, the smoking amount is an essential factor in assessing the seriousness of nicotine dependence. Additionally, the level of addition to tobacco is an important predictor of success in quitting.

The defense counsel of the tobacco companies insists that the decreasing smoking rates and increasing number of quitters are proof that anyone can easily quit smoking. The logic 
behind this statement is that as cigarette prices increase, quitting smoking can be interpreted as an economic response by consumers. However, the decrease in smoking rates does not imply that anyone can easily quit smoking. It is well known that taxation is one of the most cost-effective strategy for addiction prevention for other widely-consumed major addictive substances, including alcohol, not only tobacco [23].

Approximately $80 \%$ or more smokers try quitting smoking at some point. Nonetheless, $60 \%$ resume within a week and fewer than $5 \%$ succeed in quitting for their lifetime [4]. About half of the smokers who attempt to quit several times eventually quit smoking. This also shows that despite all their efforts to quit smoking, the other half of the smokers continue smoking, regardless of their will.

\section{CONCLUSION}

Despite the high mortality rate caused by smoking, quit rates are very low. Many smokers already meet the criteria for the diagnosis of tobacco use disorder in their late adolescence: this shows that tobacco is the cause of an addictive disorder [4]. This is because nicotine is a psychoactive and addictive substance that works in the brain neurobiologically in various ways.

The state of the art of current medical research into the structure and function of the brain, based on various research methods such as neurophysiological studies, neuroimaging studies, and neurocognitive function tests, demonstrates that changes occur in smokers' brains. Such changes include changes in the nicotine receptor; changes in the reward circuit in the midbrain and limbic system, which is strongly related to drug addiction; and structural and functional changes in the frontal lobe of the cerebrum, which governs higher cognitive functions.

Tobacco causes physical tolerance, withdrawal, loss of control, craving, and compulsive smoking behaviors. Such changes occur proportionally to the amount and duration of smoking. Therefore, the argument made by the tobacco companies that anyone can succeed in smoking with a will to quit and self-confidence is flawed and is not consistent with the scientific evidence on nicotine's influence on the brain. In conclusion, tobacco alters the human brain and causes an addictive disorder called tobacco use disorder. Smokers become dependent on nicotine regardless of their will.

\section{ACKNOWLEDGEMENTS}

This work was supported by the research fund of Hanyang University (HY-2017).

\section{CONFLICT OF INTEREST}

The author is a member of the Korean Medical Association and Korean Neuropsychiatric Association (both of which participate in the Allied Countermeasure Committee against Tobacco), a board member of the Korean Society for Research on Nicotine and Tobacco and Korean Academy of Addiction Psychiatry, and serves as a member of the advisory board for tobacco litigation of the Korea National Health Insurance Service.

\section{ORCID}

Sungwon Roh http://orcid.org/0000-0003-4557-3542

\section{REFERENCES}

1. Lim SS, Vos T, Flaxman AD, Danaei G, Shibuya K, Adair-Rohani $\mathrm{H}$, et al. A comparative risk assessment of burden of disease and injury attributable to 67 risk factors and risk factor clusters in 21 regions, 1990-2010: a systematic analysis for the Global Burden of Disease Study 2010. Lancet 2012;380(9859): 2224-2260.

2. World Health Organization. Tobacco [cited 2016 Sep 18]. Available from: http://www.who.int/mediacentre/factsheets/fs339/ en/.

3. Suh GH. Addictiveness of tobacco and smoker's ability to quit smoking. Seoul: Law Firm Shin \& Kim; 2016, p. 4-23 (Korean).

4. American Psychiatric Association. Diagnostic and statistical manual of mental disorders. 5th ed. Arlington: American Psychiatric Publishing; 2013, p. 571-577.

5. Heatherton TF, Kozlowski LT, Frecker RC, Fagerström KO. The Fagerström Test for Nicotine Dependence: a revision of the Fagerström Tolerance Questionnaire. Br J Addict 1991;86(9): 1119-1127.

6. Han ES, Foulds J, Steinberg MB, Gandhi KK, West B, Richardson $\mathrm{DL}$, et al. Characteristics and smoking cessation outcomes of patients returning for repeat tobacco dependence treatment. Int J Clin Pract 2006;60(9):1068-1074.

7. Cosgrove KP, Batis J, Bois F, Maciejewski PK, Esterlis I, Kloczyn- 
ski T, et al. $\beta 2$-nicotinic acetylcholine receptor availability during acute and prolonged abstinence from tobacco smoking. Arch Gen Psychiatry 2009;66(6):666-676.

8. Perry DC, Dávila-García MI, Stockmeier CA, Kellar KJ. Increased nicotinic receptors in brains from smokers: membrane binding and autoradiography studies. J Pharmacol Exp Ther 1999; 289(3):1545-1552.

9. Karama S, Ducharme S, Corley J, Chouinard-Decorte F, Starr $\mathrm{JM}$, Wardlaw JM, et al. Cigarette smoking and thinning of the brain's cortex. Mol Psychiatry 2015;20(6):778-785.

10. Kühn S, Schubert F, Gallinat J. Reduced thickness of medial orbitofrontal cortex in smokers. Biol Psychiatry 2010;68(11): 1061-1065.

11. Durazzo TC, Meyerhoff DJ, Nixon SJ. A comprehensive assessment of neurocognition in middle-aged chronic cigarette smokers. Drug Alcohol Depend 2012;122(1-2):105-111.

12. Nutt D, King LA, Saulsbury W, Blakemore C. Development of a rational scale to assess the harm of drugs of potential misuse. Lancet 2007;369(9566):1047-1053.

13. Lopez-Quintero C, Pérez de los Cobos J, Hasin DS, Okuda M, Wang $S$, Grant BF, et al. Probability and predictors of transition from first use to dependence on nicotine, alcohol, cannabis, and cocaine: results of the National Epidemiologic Survey on Alcohol and Related Conditions (NESARC). Drug Alcohol Depend 2011;115(1-2):120-130.

14. Lopez-Quintero C, Hasin DS, de Los Cobos JP, Pines A, Wang S, Grant $B F$, et al. Probability and predictors of remission from life-time nicotine, alcohol, cannabis or cocaine dependence: results from the National Epidemiologic Survey on Alcohol and Related Conditions. Addiction 2011;106(3):657-669.

15. Statistics Korea. Report on the social survey: health, education, safety, family, and environment. Daejeon: Gangmun Publisher; 2016, p. 94 (Korean).
16. Sadock BJ, Sadock VA, Ruiz P. Kaplan and Sadock's synopsis of psychiatry: behavioral sciences/clinical psychiatry. 11th ed. Philadelphia: Wolters Kluwer; 2015, p. 683.

17. Gonzales D, Rennard SI, Nides M, Oncken C, Azoulay S, Billing $C B$, et al. Varenicline, an alpha4beta2 nicotinic acetylcholine receptor partial agonist, vs sustained-release bupropion and placebo for smoking cessation: a randomized controlled trial. JAMA 2006;296(1):47-55.

18. Jorenby DE, Hays JT, Rigotti NA, Azoulay S, Watsky EJ, Williams $\mathrm{KE}$, et al. Efficacy of varenicline, an alpha4beta2 nicotinic acetylcholine receptor partial agonist, vs placebo or sustainedrelease bupropion for smoking cessation: a randomized controlled trial. JAMA 2006;296(1):56-63.

19. Rosenbaum P, O'Shea R. Large-scale study of freedom from smoking clinics--factors in quitting. Public Health Rep 1992; 107(2):150-155.

20. Kaprio J, Koskenvuo M. A prospective study of psychological and socioeconomic characteristics, health behavior and morbidity in cigarette smokers prior to quitting compared to persistent smokers and non-smokers. J Clin Epidemiol 1988;41(2): 139-150.

21. Farkas AJ, Pierce JP, Zhu SH, Rosbrook B, Gilpin EA, Berry C, et al. Addiction versus stages of change models in predicting smoking cessation. Addiction 1996;91(9):1271-1280.

22. Borland R, Yong HH, O'Connor RJ, Hyland A, Thompson ME. The reliability and predictive validity of the Heaviness of Smoking Index and its two components: findings from the International Tobacco Control Four Country study. Nicotine Tob Res 2010;12 Suppl:S45-S50.

23. Babor TF, Caetano R. Evidence-based alcohol policy in the Americas: strengths, weaknesses, and future challenges. Rev Panam Salud Publica 2005;18(4-5):327-337. 